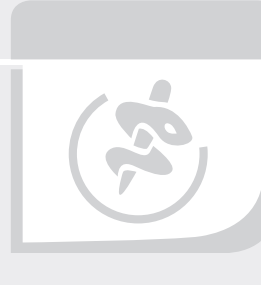

Thieme

\title{
Aggravierung eines venösen Ulkus mit Phlebo-Lymphödem durch einschnürendes Halteband eines Urinbeutels
}

Die 96-jährige Patientin stellte sich mit einem seit etwa 2 Monaten größenprogredienten Ulkus am rechten Unterschenkel prätibial und zunehmender Beinschwellung rechts vor. In der körperlichen Untersuchung zeigten sich ein $4 \times 3 \mathrm{~cm}$ großes Ulkus mit mazeriertem Rand und ein deutliches Ödem des rechten Unterschenkels mit positivem Stemmer-Zeichen und Kastenzehen.

Trotz 1-mal täglicher manueller Lymphdrainage und Lokaltherapie des Ulkus mit Polihexanidsalbe/Fettgaze und Pütter-Verbänden und chirurgischem Wunddebridement kam es über mehrere Tage zu keiner wesentlichen Besserung des Befundes. Eine intermittierende pneumatische Kompressionstherapie konnte aufgrund einer MRSA-Besiedelung des Ulkus nicht durchgeführt werden.

In der dann folgenden phlebologischen Mitbeurteilung fiel ein deutliches Ödem nicht nur des rechten Unterschenkels, sondern auch des Oberschenkels auf. Am proximalen rechten Oberschenkel befand sich ein mit einem straffen, schmalen Haftband befestigter Urinbeutel. Oberhalb der Einschnürung zeigte sich dagegen nur noch wenig Ödem. Bei genauerem Nachfragen berichtete die Patientin, dass die Befundverschlechterung am Bein zeitgleich mit dem dauerhaften Tragen dieses Haftbandes vor etwa 2 Monaten begonnen habe.

Eine tiefe Beinvenenthrombose wurde duplexsonografisch ausgeschlossen. Sichtbare Ulkus-relevante Varizen zeigten sich nicht.

Nach Entfernung des Haftbandes kam es innerhalb weniger Tage zu einer deutlichen Verbesserung sowohl des Ulkus als auch des Ödems (Reduktion des Beinum-

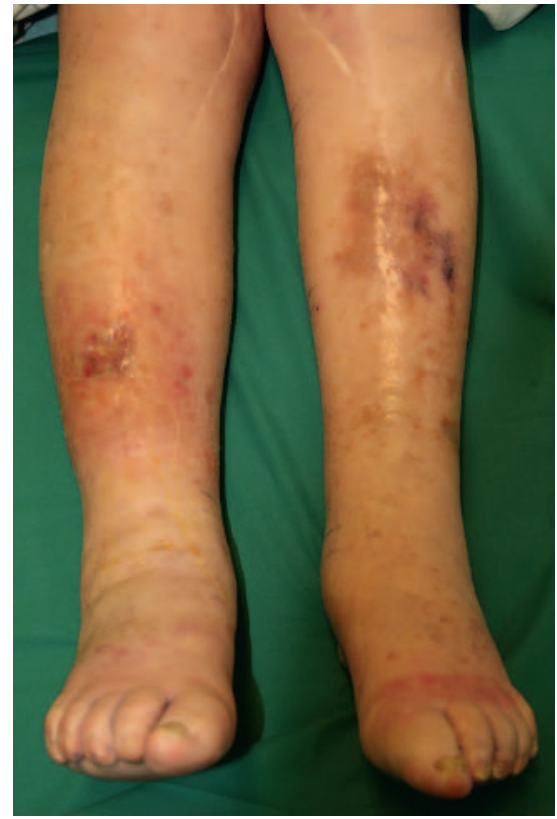

- Abb. 1 Ansicht der Unterschenkel beidseits mit Ulkus am rechten Unterschenkel unter Therapie, 3 Tage nach Entfernung der Abschnürung.

fangs am rechten Unterschenkel um $3 \mathrm{~cm}$ ) unter Fortführung der begonnenen Lokal-, Entstauungs- und Kompressionstherapie ( Abb. 1, 2).

\section{Fazit}

Abschnürungen und Schnürfurchen können durch eine inadäquate Kompressionstherapie (mangelhaft angelegte Verbände oder Kompressionsstrümpfe) oder auch unsachgemäße Anwendung von anderen Utensilien, mitunter auch seitens des Patienten, entstehen (z. B. Gummibänder, Paketklebeband). Im vorgestellten Fall kam es durch ein verordnetes Hilfsmittel (Urinbeutel bzw. dessen Befestigung) zu einer progredienten Problematik. Alternativen zu dem hier verwendeten, sehr stramm anliegenden und schmalen Gum-

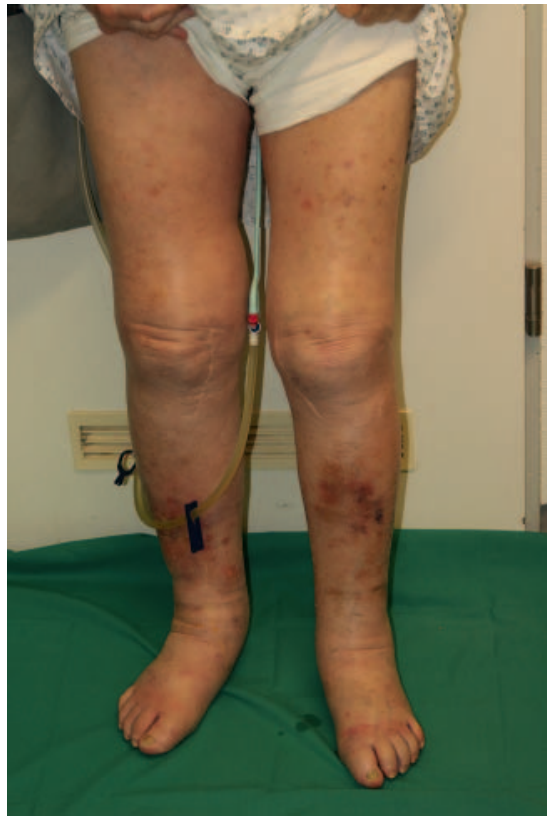

- Abb. 2 Ansicht der Beine mit angelegtem Urinbeutel (Halteband am rechten proximalen Oberschenkel nicht sichtbar, nur für das Foto erneut passager angelegt), Rest-Ödem am gesamten rechten Bein, 3 Tage nach Entfernung der Abschnürung und unter Therapie (Entstauung, Kompression, lokale Wundtherapie).

miband können speziell optimierte Urinbeutel-Befestigungen schaffen, die flächig an Bein oder Rumpf angebracht oder an einem Hüftgurt befestigt werden können. Der dargestellte Fall verdeutlicht, wie wichtig eine vollständige körperliche Untersuchung und die Kenntnis darüber ist, dass derartige Abschnürungen problematisch werden können.

Interessenkonflikt

Die Autorinnen/Autoren geben an, dass kein Interessenkonflikt besteht. 
Autoren

\section{A. L. Recke}

Institut

Klinik für Dermatologie, Venerologie und Allergologie, UKSH Campus Lübeck
Dr. med. A. L. Recke

Klinik für Dermatologie, Venerologie und

Allergologie

UKSH Campus Lübeck

Ratzeburger Allee 160

23538 Lübeck

Anna.Recke@uksh.de
Bibliografie

DOI https://doi.org/10.1055/a-1170-6840

Online-Publikation: 25.5.2020

Phlebologie 2020; 49: 249-250

(c) Georg Thieme Verlag KG, Stuttgart · New York ISSN 0939-978X 